International Journal of Child, Youth and Family Studies (2016) 7(2): 171-177

DOI $10.18357 /$ ijcyfs 72201615716

\title{
INTRODUCTION TO THE SPECIAL ISSUE ON ALTERNATIVE PATHWAYS IN EDUCATION FOR DISENFRANCHISED CHILDREN AND YOUNG PEOPLE IN THE AUSTRALIAN CONTEXT
}

\author{
Marnee Shay, Ann Morgan, Jo Lampert and Deborah Heck
}

Marnee Shay (corresponding author) is a Lecturer in the School of Cultural and Professional Learning at Queensland University of Technology, Kelvin Grove, Brisbane. Email:

ms.shay@qut.edu.au

Ann Morgan, PhD, is Staff Formation and Professional Learning Coordinator across four Flexi Schools in the Youth+ Schools Network, PO Box 498, Red Hill, Qld 4059, Australia. Email:

ann.morgan@youthplus.edu.au

Jo Lampert, PhD is an Associate Professor Schools in the Faculty of Education at Queensland University of Technology, Kelvin Grove, Brisbane. Email: i.lampert@qut.edu.au

Deborah Heck is an Associate Professor, Education/Portfolio Leader, Postgraduate and Higher Degrees by Research (HDR) programs at the Faculty of Science, Health, Education and Engineering, University of the Sunshine Coast, Queensland, Australia. Email:

dheck@usc.edu.au 
International Journal of Child, Youth and Family Studies (2016) 7(2): 171-177

DOI $10.18357 /$ ijcyfs 72201615716

This special issue explores alternative pathways in education for disenfranchised children and young people. The papers presented are from Australia and Canada. The issue aims to contribute to a growing field of study around the provision of education programs to underserved youth, and to recognise the contributions of scholars, educators, practitioners, and young people whose voices have been under-represented.

Alternative education is the umbrella term used in the literature that describes models of education operating outside conventional schooling. These approaches range along a continuum. They include models focused on changing young people to fit the dominant education paradigm through to models that aim to change the provision of education to meet the needs of young people (te Riele, 2007). Many young people internationally are disenfranchised from education. They experience multiple challenges that limit their access and engagement in education. The promotion of neoliberal agendas in education that narrowly determine the "success" of students based on outcomes related to how they perform on high stakes tests has resulted in the disenfranchisement of young people globally (Lingard, Sellar, \& Savage, 2014). In Australia, young people who are over-represented in alternative education include those who have experienced a range of complexities such as: poverty; homelessness; substance misuse; domestic and family violence; generational unemployment; involvement in the criminal justice system; involvement in the child protection system, foster care, or both; special needs; and mental health issues. Young people who are refugees, LGBTIQ ${ }^{1}$, First Nations, or speak English as an additional language are more likely to engage in alternative education pathways.

The emergence of a critical mass of young people who have disengaged from schooling has resulted in rapid expansion of the alternative education sector. In Australia the need for education alternatives for young people who have been disenfranchised has resulted in an increasing number of programs with differing aims and features (te Riele, 2014). Accompanying the expansion of programs is an emerging body of research. Common perspectives adopted in research to date can be summarised in three general areas: research portraying young people's experience and viewpoint; research foregrounding program features, typologies, and program evaluation; and research presenting a critical perspective on sociological, ideological, political, and policy issues impacting upon young people's experiences in education (Morgan, 2013).

While alternative education research is an emerging field, there is a plethora of education research on pedagogy and practice that remains centred on mainstream contexts and discourses. This focus on mainstream settings has left a wide gap in the corpus of research on practices in alternative school settings. Scholars such as Lampert and Burnett (2015) outline the importance of having informed, reflective, and well prepared educators in schools that are in lowsocioeconomic or high-poverty areas. Many alternative schools and programs are situated in

${ }^{1}$ LGBTIQ — lesbian, gay, bisexual, trans, intersex, or queer. 
International Journal of Child, Youth and Family Studies (2016) 7(2): 171-177

DOI $10.18357 /$ ijcyfs 72201615716

low-socioeconomic communities. Therefore, more research is needed to examine effective teaching and learning practice with disenfranchised and marginalised youth, to understand whether this practice differs in mainstream and alternative education settings.

Recent research in this emerging sector has focussed on specific aspects of pedagogy that have proven to be effective for re-engagement of young people who are disadvantaged by mainstream education systems (Mills \& McGregor, 2013; Shay 2015, 2016). A shift that we have observed, and that is reflected in papers in this special issue, is a growing sense of confidence regarding what this context has to offer mainstream education settings. This shift is based on research highlighting the breadth of practice experience that can inform and revitalise new approaches to engagement and inclusion of young people in any education setting (Mills, McGregor, Baroutsis, te Riele, \& Hayes, 2015; Morgan, Pendergast, Brown, \& Heck, 2014, 2015; Shay, 2015). This issue presents some of the emerging trends in research. The notion of how work in this sector can positively influence systemic change that enhances learning outcomes for young people is a strong theme. The areas of trauma informed practice, relevant and meaningful pedagogy, and a focus on staff professional development and wellbeing are included.

\section{Mechanisms at Play in Flexible Learning Settings: Options to Inform Practice in Mainstream School Systems}

In the first two papers of this special issue, Zyngier, Black, Brubaker and Pruyn, and Mills and McGregor, offer overviews of the diverse range of alternative and flexible programs within mainstream schools and those offered in independent special assistance schools and standalone programs. While the authors of both papers consider effective features of this rapidly expanding education sector, they emphasise the unique aspects of practice that could inform mainstream contexts in working with disenfranchised young people. They "speak back" to systemic issues that remain as barriers to the inclusion of disenfranchised young people in mainstream education contexts. The papers explore the lessons learnt from flexible and alternative programs and highlight strategies that may also support young people in mainstream settings before they experience failure and exclusion. The papers consider specific insights from research conducted in this sector that offer proactive options and strategies for inclusion of disenfranchised young people.

Three conceptual headings are used by Zyngier et al. to synthesise research on alternate "pull-out" programs and how these contribute to students' sense of efficacy with respect to their learning, wellbeing. and pathways. Through these concepts, Zyngier and colleagues address: programs' sustainability — their stickability; programs' effectiveness in terms of whether their stated outcomes are achieved — their transformability; and how programs might be reproduced successfully in other locations - their transmittability. The authors offer recommendations for future practice and a challenge to wider school systems to prioritise prevention and early intervention to support the needs of vulnerable students. They argue that changes by broader 
International Journal of Child, Youth and Family Studies (2016) 7(2): 171-177

DOI $10.18357 /$ ijcyfs72201615716

school systems and teachers within them must be informed by the perspectives of young people who are disengaged from schooling.

Mills and McGregor present two case studies of flexible learning programs in Queensland showing two different models of alternative schooling — one an independent Special Assistance School and the other an annex model of alternative provision sponsored by a local high school. The data were drawn from a larger study of alternative education provision in Queensland involving 12 case study schools in differing locations across the state. Once again, an emerging objective identified in this paper is to use what is happening in the growing field of flexible education provision to inform, in a positive way, the practice of mainstream schools when dealing with vulnerable students.

\section{Youth-centred Relational Pedagogy: Trauma-Informed Practice}

Key insights into youth-centred relational pedagogy are emerging through research on different ways of working with young people in alternative and flexible learning options in Australia. In particular, growing interest in the benefits of trauma-informed practice and its significance for young people who have experienced failure and exclusion from mainstream educational contexts is starting to be addressed in education research. This special issue highlights the importance of trauma-informed education and practice. The third and fourth papers describe trauma-informed teaching approaches in two contrasting settings.

Brunzell, Stokes and Waters present the implementation of a trauma-informed positive education (TIPE) approach to classroom teaching with flexible learning teachers. An underlying focus of the study reported in this paper is the practice strategies that teachers in "traumaaffected flexible learning settings" can employ to enhance young people's regulatory ability. They contend that, as young people increase their ability to self-regulate, their potential to achieve successful learning outcomes is enhanced. Through this positive approach to engagement, teachers can identify specific practice strategies to implement in their classrooms. The strategies are related to four sub-themes: rhythm; self-regulation; mindfulness; and deescalation.

In contrast, Gribble and English offer insights into the significance of trauma-informed practice through a case study that explores the benefits of home education. In Australia, significant numbers of children and young people are in out-of-home care. The authors challenge the view that formal or mainstream education offers the best support for these young people. Gribble and English argue that good educational outcomes and recovery for children and young people in out-of-home care can be achieved effectively through home education. They assert that home education offers a low-stress environment and individual learning that more effectively addresses the complex needs of children and young people who have experienced the impact of trauma from abuse, neglect, and maltreatment. 
International Journal of Child, Youth and Family Studies (2016) 7(2): 171-177

DOI $10.18357 /$ ijcyfs72201615716

\section{Research Focussing on the Experiences and Perspectives of Multidisciplinary Staff Working in Alternative and Flexible Learning Programs}

The final three papers of this special issue, which explore alternative pathways in education for disenfranchised children and young people, provide a shift in focus towards the work and learning of multidisciplinary staff in these settings. Educators' experiences with disenfranchised young people influence their professional judgement in relation to pedagogy, professional learning, and the underpinning philosophy that shapes practice.

To address the needs of disenfranchised young people, multidisciplinary staff in alternative settings frequently explore responsive forms of education provision that are relevant and meaningful. Talbot and Hayes provide a phenomenographic analysis of the experiences of teachers in alternative schools as they engage young people through inquiry-based pedagogies. The sustainability of this approach is considered in light of the various challenges and demands experienced by teachers as they adopt this pedagogy. The experiences of staff are highlighted as they navigate the inherent tensions associated with balancing the needs and interests of young people with staff capacity, program resources, and the challenge of demonstrating learning outcomes.

Related to the wellbeing needs of staff in alternative education, Wandell outlines a proposed pilot study of a Gratitude Practice Program. In this paper, Wandell draws on her considerable practice experience in flexible learning contexts in the field of positive psychology to address the problem of staff burnout. Professional learning designed for staff wellbeing is identified as an important preventative strategy in the context of alternative and flexible learning options as staff require the capacity to deal with high levels of complexity. Wandell's proposed pilot study highlights the diverse range of necessary skills that have the potential to enhance staff wellbeing, and their capacity to engage positively and responsively with disenfranchised young people.

The final paper in this special issue of the IJCYFS features research conducted in Australia and Canada. Vadeboncoeur and Vellos identify and elaborate on a specific quality of student-teacher relationships commonly encountered in this sector. Framed as the principle of accept and build, it enables students to "imagine and create new social futures" in and through relationship with staff. Challenging the stereotypical labelling that regards alternative education as providing a "second chance" for marginal students, the authors argue that reciprocal, two-way relational work is in fact central to teaching and learning regardless of the context — alternative or mainstream - in which it occurs. The experience of intentionally focussing on the quality of student-teacher relationships in this sector offers new and different insights into engagement and inclusion of those who commonly experience failure and exclusion in mainstream schools.

This special issue would not have been possible without the assistance, support, and trust afforded to us as guest editors by the Editor of the IJCYFS, Professor Sibylle Artz, and the 
International Journal of Child, Youth and Family Studies (2016) 7(2): 171-177

DOI $10.18357 /$ ijcyfs72201615716

School of Child and Youth Care at the University of Victoria in British Columbia. We would like to acknowledge Aunty Denise Proud, who accompanied us on a study tour to Canada. Through Aunty Denise's wide range of international contacts, she was instrumental in connecting us with Professor Artz. In gratitude we also acknowledge the additional support provided through the mentoring relationships with Associate Professors Jo Lampert (Queensland University of Technology) and Deborah Heck (University of the Sunshine Coast), who were also on the team of guest editors for this special issue. The generous contribution of Dr. Megan Kimber, QUT, through her expertise in copyediting, is gratefully acknowledged. We acknowledge the support we have received from practitioners - those who do the day-to-day work in alternative settings. Finally, we honour the young people and their families/carers who continue to inspire our commitment to research and practice in this dynamic field of alternative pathways in education. 
International Journal of Child, Youth and Family Studies (2016) 7(2): 171-177

DOI $10.18357 /$ ijcyfs72201615716

\section{References}

Lampert, J., \& Burnett, B. (2015). Teacher education for high poverty schools. Dordrecht, Netherlands: Springer Press.

Lingard, B., Sellar, S., \& Savage, G. (2014). Re-articulating social justice as equity in schooling policy: The effects of testing and data infrastructures. British Journal of Sociology of Education, 35(5), 710-730. doi:10.1080/01425692.2014.919846

Mills, M., \& McGregor, G. (2013). Re-engaging young people in education: Learning from alternative schools. Oxon, UK: Routledge.

Mills, M., McGregor, G., Baroutsis, A., te Riele, K., \& Hayes, D. (2015). Alternative education and social justice: Considering issues of affective and contributive justice. Critical Studies in Education. Online publication, 21 October, 2015. doi:10.1080/17508487.2016.1087413

Morgan, A. (2013). Different ways of being educator: A sociocultural exploration of educator identity and development in practice, in a system of non-traditional flexi schools (Unpublished doctoral dissertation). Griffith University, Brisbane, Australia.

Morgan, A., Pendergast, D., Brown, R., \& Heck, D. (2014). The art of holding complexity: A contextual influence on educator identity and development in practice in a system of alternative 'flexi' schools. Reflective Practice: International and Multidisciplinary Perspectives, 15(5), 579-591. doi:10.1080/14623943.2014.900020

Morgan, A., Pendergast, D., Brown, R., \& Heck, D. (2015). Relational ways of being an educator: Trauma-informed practice supporting disenfranchised young people. International Journal of Inclusive Education, 19(10), 1037-1051. doi:10.1080/13603116.2015.1035344

Shay, M. (2015). The perceptions that shape us: Strengthening Indigenous young people's cultural identity. In T. Ferfolja, C. Jones-Diaz, \& J. Ullman (Eds.), Understanding Sociological Theory and Pedagogical Practices (pp. 93-105) Melbourne, Australia: Cambridge University Press.

Shay, M. (2016). Reimagining Indigenous education through flexi schooling. In D. Bland (Ed.), Imagination for inclusion: Diverse contexts of educational practice (pp. 116-127). Oxon, UK: Routledge.

te Riele, K. (2007). Educational alternatives for marginalised youth. Australian Educational Researcher, 34(3), 53-68.

te Riele, K. (2014). Putting the jigsaw together: Flexible learning programs in Australia (Final report). Melbourne, Australia: The Victoria Institute, Victoria University. 